\title{
HYPOTENSIVE RESPONSE IN SPONTANEOUSLY HYPERTENSIVE RATS FOLLOWING MICROINJECTION OF $\alpha$-METHYLNORADREN- ALINE IN THE CAUDAL BRAIN-STEM
}

\section{PIETER ZANDBERG* and WYBREN DE JONG}

Rudolf Magnus Institute for Pharmacology, Medical Faculty, University of Utrecht, Vondellaan 6, 3521 GD Utrecht (The Netherlands)

(Received June 5th, 1979)

(Accepted June 12th, 1979)

\section{SUMMARY}

Local microinjection of $1.25 \mathrm{nmol}(-)-\alpha$-methylnoradrenaline in the $\mathrm{A}_{2}$-region of the nucleus tractus solitarii (NTS) caused a decrease of blood pressure and heart rate in both spontaneous hypertensive rats (SHR) and Wistar-Kyoto $(\mathrm{W} / \mathrm{K})$ rats. Although the maximal responses in both strains did not differ, the decrease in blood pressure lasted longer in the SHR. These results do not support the concept of a diminished sensitivity of catecholaminergic receptors in the NTS of SHR to $\alpha$-methylnoradrenaline.

We have shown that the local administration of various catecholamines to the $A_{2}$-region of the nucleus tractus solitarii (NTS) dose-dependently decreased the blood pressure and heart rate of a normotensive strain of Wistar rats $[1,9,10]$. A dysfunction of catecholaminergic transmission has been suggested to play a role in the development of hypertension in SHR [8]. We therefore tested whether the effect on blood pressure and heart rate differed in SHR and W/K rats following the microinjection of $\alpha$-methylnoradrenaline into the $\mathrm{A}_{2}$-region of the NTS of the medulla oblongata.

Male spontaneously hypertensive rats (SHR-NIH Cpb) were used with Wistar-Kyoto rats (W/K-NIH Cpb) as normotensive controls (19 weeks old) (for genealogy see [2]). All rats were obtained from the Centraal Proefdierenbedrijf TNO, Zeist, The Netherlands.

The rats were anesthetized with pentobarbital $(25 \mathrm{mg} / \mathrm{kg})$ given i.p. with a supplemental dose $(2.5 \mathrm{mg} / \mathrm{kg}$ i.v. $)$ as described by Judy et al. [3]. These authors showed that such doses of pentobarbital did not materially affect

Address correspondence to: P. Zandberg., National Institute of Public Health, Laboratory of Pharmacology, P.O. Box 1, 3720 BA Bilthoven, The Netherlands. 
the blood pressure level of SHR and also had little or no effect on the sympathetic outflow or the baroreceptor reflex. Higher doses of pentobarbital and several other anesthetics however are less suitable for anesthetizing SHR since they may depress the blood pressure markedly. An indwelling polyethylene cannula was placed in the femoral artery and the blood pressure was recorded from this cannula by means of a Statham transducer (P23Db) connected to a Grass polygraph. The heart rate was computed from the blood pressure pulse wave by means of a biotachometer. For the microinjections the rats were placed in a stereotactic apparatus and the head was flexed at an angle of $45^{\circ}$ downward. The dorsal surface of the lower brain-stem was exposed by a limited occipital craniotomy. Microinjections of $1.25 \mathrm{nmol}(-)-\alpha$-methylnoradrenaline in the area of the NTS were given through a glass cannula (outer diameter $60 \mu \mathrm{m}$ ) in a volume of $0.4 \mu \mathrm{l}$ delivered in $10 \mathrm{sec}$ with an Agla micrometer syringe and a Sharlow micrometer. The injections into the $\mathrm{A}_{2}$-region were made unilaterally (on the right side of the medulla) or bilaterally at the level of the caudal tip of the area postrema, just medial to the tractus solitarius $(0.5 \mathrm{~mm}$ lateral of the midline and $0.9 \mathrm{~mm}$ below the dorsal surface of the medulla oblongata). A localization study with $\alpha$-methylnoradrenaline had previously shown that this was the part of the NTS in which injections of $\alpha$-methylnoradrenaline were most effective [9]. A dose of $1.25 \mathrm{nmol}$ of this compound was used in the present study since the effect of this dose was about in the middle of the response curve.

Each rat received only one unilateral or bilateral injection. After termination of the experiments the rats were killed by decapitation. The brain was removed from the skull and fixed in $4 \%$ formalin. Frozen sections $(60 \mu \mathrm{M})$ were cut and stained with $0.1 \%$ thionine, after which the lesions and needle tracks were observed microscopically. Data are reported as means \pm S.E.M. Student's $t$-test was used for statistical analysis of the results.

The basal values for blood pressure and heart rate just before the injections were made into the NTS are shown in Table I. Local injections of saline did not change the blood pressure and heart rate significantly. Unilateral as well as bilateral injections of $(-)-\alpha$-methylnoradrenaline $(1.25$ $\mathrm{nmol}$ ) into the $\mathrm{A}_{2}$-region of the NTS caused a significant decrease in blood pressure and heart rate in SHR and $\mathrm{W} / \mathrm{K}$ rats. Maximal effects on both blood pressure and heart rate were obtained within 5-10 min following injection as had been seen in normotensive Wistar rats anesthetized with urethane [10]. After bilateral administration of $(-)-\alpha$-methylnoradrenaline $(2 \times 1.25 \mathrm{nmol})$ the decrease in blood pressure in both groups of rats was more pronounced than after unilateral administration. There was no difference in the maximal decrease of blood pressure between the two strains. The hypotensive effect however lasted longer in SHR than in W/K rats, after both unilateral and bilateral application. The pattern of the blood pressure response of the $\mathrm{W} / \mathrm{K}$ rat was comparable to that of the normal Wistar rat [10]. In SHR the maximal decrease in heart rate 5 min after 


\section{TABLE I}

BASAL VALUES FOR BLOOD PRESSURE AND HEART RATE OF SPONTANEOUSLY HYPERTENSIVE RATS (SHR) AND WISTAR-KYOTO RATS AND THE DECREASE IN BLOOD PRESSURE CAUSED BY UNILATERAL AND BILATERAL INJECTIONS OF $1.25 \mathrm{nmol}(-)-\alpha$-METHYLNORADRENALINE IN THE $A_{2}$-REGION OF THE NUCLEUS TRACTUS SOLITARII (NTS)

\begin{tabular}{|c|c|c|c|c|c|c|c|}
\hline & \multirow{2}{*}{$\begin{array}{l}\text { Mean } \\
\text { blood } \\
\text { pressure } \\
\text { (mmHG) }\end{array}$} & \multirow{2}{*}{$\begin{array}{l}\text { Heart } \\
\text { rate } \\
\text { (bpm) }\end{array}$} & \multicolumn{5}{|c|}{$\Delta$ Blood pressure after } \\
\hline & & & 5 & 10 & 15 & 20 & $30 \mathrm{~min}$ \\
\hline \multicolumn{8}{|l|}{ Unilateral } \\
\hline $\begin{array}{l}\text { Wistar- } \\
\text { Kyoto }\end{array}$ & $116 \pm 4^{\mathrm{d}}$ & $361 \pm 13$ & $-23 \pm 3$ & $-20 \pm 3$ & $-16 \pm 2$ & $-10 \pm 2$ & $-5 \pm 3$ \\
\hline SHR & $179 \pm 4^{b}$ & $359 \pm 14$ & $-24 \pm 3$ & $-28 \pm 2^{b}$ & $-25 \pm 2^{b}$ & $-21 \pm 2^{b}$ & $-18 \pm 3^{b}$ \\
\hline \multicolumn{8}{|l|}{ Bilateral } \\
\hline $\begin{array}{l}\text { Wistar- } \\
\text { Kyoto }\end{array}$ & $102 \pm 4$ & $353 \pm 12$ & $-36 \pm 4$ & $-27 \pm 3$ & $-18 \pm 2$ & $-11 \pm 3$ & $-5 \pm 5$ \\
\hline SHR & $164 \pm 3$ & $379 \pm 13$ & $-37 \pm 5$ & $-38 \pm 4$ & $-27 \pm 4$ & $-22 \pm 4^{b}$ & $-19 \pm 5^{b}$ \\
\hline
\end{tabular}

a Mean \pm S.E.M. of $6-7$ animals.

${ }^{b}$ Is significantly $(P<0.05)$ different from the Wistar-Kyoto control.

injection was $-28 \pm 8 \mathrm{bpm}$ and $-61 \pm 10 \mathrm{bpm}$ following unilateral and bilateral application respectively. The values for $W / K$ rats were $-36 \pm 8 \mathrm{bpm}$ and $-38 \pm 9 \mathrm{bpm}$ respectively.

A dysfunction of catecholaminergic transmission has been suggested to play a role in the development of hypertension in SHR [8]. In the adult SHR the concentration of noradrenaline, dopamine and adrenaline [6] in the $A_{2}$-region of the NTS is higher than that in the normotensive $W / K$ rats. The $A_{2}$-region contains catecholaminergic cell bodies [4] and has relatively high concentrations of dopamine, noradrenaline [7] and adrenaline [5]. Furthermore it receives the major part of the afferent sino-aortic baroreceptor fibres [4]. The present results indicate that the catecholaminergic receptor sites of the $A_{2}$-region of the NTS of SHR are no less sensitive to $\alpha$-methylnoradrenaline than are those of $\mathrm{W} / \mathrm{K}$ controls. The longer duration of the hypotensive response may be related to a dysfunction in catecholaminergic mechanisms in this region of the adult SHR. Although an increased number of receptor sites or an enhanced sensitivity of these receptor sites could play a role herein such an explanation appears unlikely since the maximal effect was not increased. The hypotensive responses may however last longer in SHR because they are less readily opposed by an increased cardiac output and/or peripheral resistance in the systemic circulation in SHR than in control $\mathrm{W} / \mathrm{K}$ rats. 


\section{REFERENCES}

1 de Jong, $W$. Noradrenaline, central inhibitory control of blood pressure and heart rate, Europ. J. Pharmacol., 29 (1974) 179-181.

2 de Jong, W., Nijkamp, F.P. and Bohus, B. Role of noradrenaline and serotonin in the central control of blood pressure in normotensive and spontaneously hypertensive rats, Archs. int. Pharmacodyn. Ther., 213 (1975) 272-284.

3 Judy, W.V., Watanabe, A.M., Henry, D.P., Besch, H.R., Murphy, W.R. and Hockel, G.M., Sympathetic nerve activity - role in regulation of blood pressure in the spontaneously hypertensive rat, Circulat. Res., 38, Suppl. II (1976) 21-29.

4 Palkovits, M. and Záborszky, L., The neuro anatomy of central cardiovascular control: the nucleus tractus solitarii; afferent and efferent neuronal connections in relation to the baroreceptor reflex arc. In W. de Jong, A.P. Provoost and A.P. Shapiro (Eds.), Hypertension and Brain Mechanisms, Progress in Brain Research, Volume 47, Elsevier, Amsterdam, 1977, pp. 9-34.

5 van der Gugten, J., Palkovits, M., Wijnen, H.J.L.M. and Versteeg, D.H.G., Regional distribution of adrenaline in rat brain, Brain Res., 107 (1976) 171-175.

6 Versteeg, D.H.G., Palkovits, M., van der Gugten, J., Wijnen, H.J.L.M., Smeets, G.W.M. and de Jong, W., Catecholamine content of individual brain regions of spontaneously hypertensive rats (SH-rats), Brain Res., 112 (1976) 429-434.

7 Versteeg, D.H.G., van der Gugten, J., de Jong, W. and Palkovits, M., Regional concentrations of noradrenaline and dopamine in rat brain, Brain Res., 113 (1976) $563-574$.

8 Yamori, Y., Lovenberg, W. and Sjoerdsma, A., Norepinephrine metabolism in brainstem of spontaneously hypertensive rats, Science, 170 (1970) 544-546.

9 Zandberg, $P$. and de Jong, $W$., $\alpha$-Methylnoradrenaline-induced hypotension in the nucleus tractus solitarii of the rat: a localization study, Neuropharmacology, 16 (1977) 219-222.

10 Zandberg, P., de Jong, W. and de Wied, D., Effect of catecholamine-receptor stimulating agents on blood pressure after local appplication in the nucleus tractus solitarii of the medulla oblangata, Europ. J. Pharmacol, in press. 